\title{
DOME OVER THE GDYNIA SEAPORT BUILDING
}

\author{
T. GODYCKI-ĆWIRKO ${ }^{1}$, K. NAGRODZKA-GODYCKA ${ }^{2}$, P. PIOTRKOWSKI ${ }^{3}$
}

\begin{abstract}
The paper presents the description of structure and the selected problems of the technical condition, as well as the strength analysis of the thin-walled reinforced concrete shell which has been making a covering of the main hall of the Gdynia Seaport Building through the last 80 years. The rectangle projection of four single curvature shells of the dome was shaped out of mutual perpendicular intersection of two cylindrical shells.

The analysis of the state of stress and deformations was carried out using the special model worked out in MES considering the combination of loads, the thermal ones included. For the long lasting loads (the deadweight of the dome), the computed results of static quantities were confronted with analytical results obtained according to F. Dischinger's method. This method had been applied by the DYWIDAG Company in Berlin and its branch in Katowice (Poland) who designed the Gdynia Dome.

The computational analysis and the assessment of the technical state, along with laboratory $\mathrm{pH}$ tests of concrete, made it possible to carry out the overall evaluation of durability and safety of operation of the Gdynia Seaport Dome through the next decades.
\end{abstract}

Keywords: reinforced concrete, dome, shell, ribs.

\section{Historical Feature}

The reinforced concrete multilateral domes were designed and constructed by F. Dischinger (DYWIDAG Company, Berlin) as the first ones in the $20^{\text {th }}$ of the XX century. The most well-known domes of that period were covering the markets in Leipzig and Basel which formed regular octagon out of four horizontally intersected cylindrical shells $(\mathrm{n}=4)$. The analytical method of design worked out by Dischinger was published in [1], [2], and the execution of the Leipzig dome was described with participation of H. Rüsch in [3]. The abstract of the Dischinger's method compiled by W. Stachurski was published in Polish in [4].

\footnotetext{
1 Department of Concrete Structures, Gdansk University of Technology, Poland.

2 Department of Concrete Structures, Gdansk University of Technology, Poland, e-mail: ngodyc@pg.gda.pl

3 Department of Concrete Structures, Gdansk University of Technology, Poland, e-mail: piotrkow@pg.gda.pl
} 
The dome over the Gdynia Seaport Building (Figure 1) was designed in 1932 by Dyckerhoff und Widman joint stock company, the Katowice branch of DYWIDAG. The construction of the dome was executed by the Skąpski, Wolski, Wiśniewski Polish Company in 1933, and was ceremoniously commissioned for exploitation on December 8 in the presence of 5 ministers, including J. Beck and F. Zarzycki, among the others. Such quick execution was an unimaginative achievement in those times.

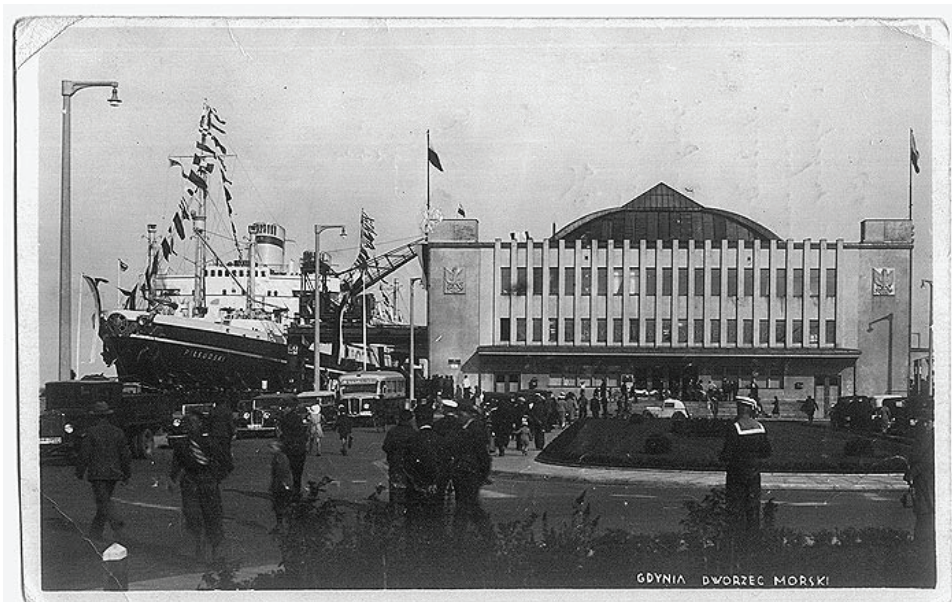

Fig. 1. The Gdynia Seaport Building, 1933 (http://www.ronet.pl/)

Unfortunately the design and executive documentation of the Gdynia Seaport were lost during the World War II. The postwar documentation of the reconstruction of damages of a part of the dome (the circumference beam and fragment of the shell on the French Quay) were lost too. The damages were caused by the alliance bombings of October, 1943 and December, 1944 of the then -,Kriegsmarine-Gotenhafen” naval base. In such a situation, the authors of this study had to make use of the precise inventory [6], local inspection, and current geodetic measurements of the present state of the building in the aspect of safety and usefullness for the further its exploatation as the Museum of Emigration.

\section{GEOMETRY OF THE GDYNIA SEAPORT DOME}

The Gdynia Seaport Dome was geometrically formed of two cylindrical shells intersected at a right angle $(\mathrm{n}=2)$, since the hall to be covered was of rectangle in plane. The number of the interrib shells was in this case $2 n=4$ (Figure 2).

The geometry and the state of stress was complicated by the pyramidal skylight of the height of about $4.0 \mathrm{~m}$, situated on the reinforced concrete grid mesuring $6.3 \times 8.3$ 
$\mathrm{m}$, forming a rectangle connected on the perimeter to the shell, and with four ribs at the corners, situated at the top of the shells. While the base of the ribs and the edges of shells were supported on circumferential beams $20.1 \mathrm{~m}$ x $18.1 \mathrm{~m}$ long with unsusceptable vertical displacements (Figure 3).
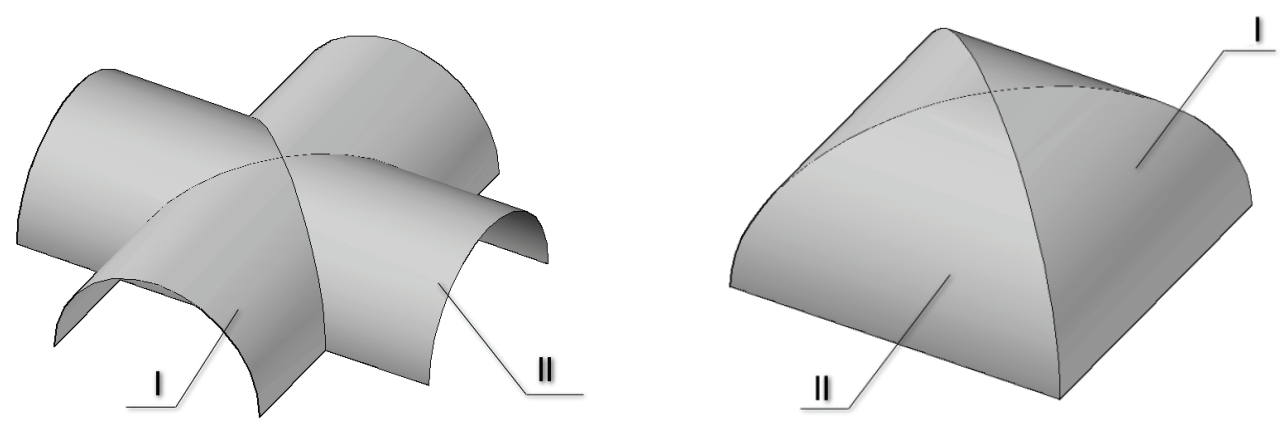

Fig. 2. Cylindrical shells I-II in the form of perpendicular intersection of the four-wall dome over the Gdynia Seaport Building

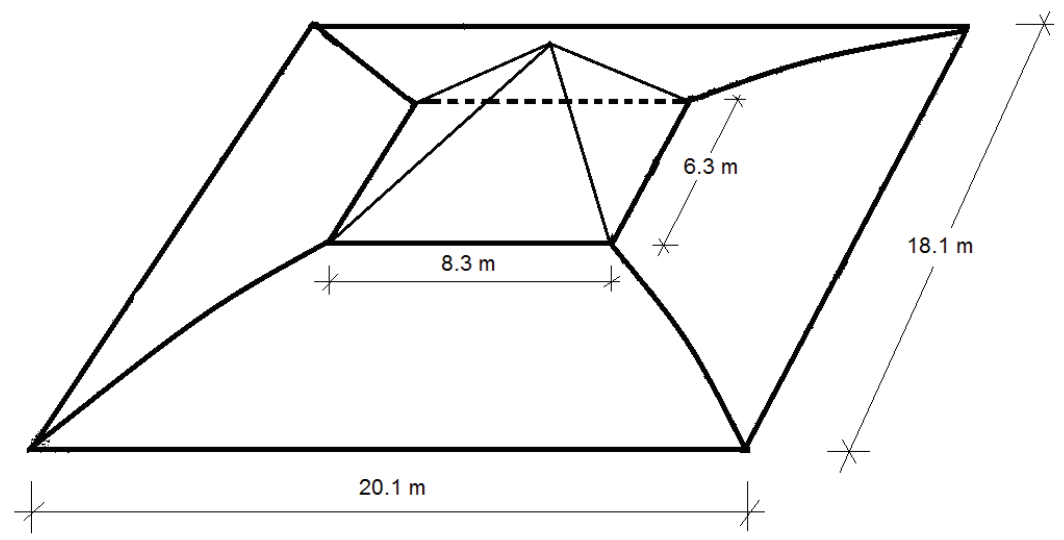

Fig. 3. Geometry of the four segment shell with the glazed steel pyramidal skylight

\section{THE SKYLIGHT}

\section{Reinforced concrete grid}

In Figure 4, the reinforced concrete grid of beams of cross-section $b \times h=200 \times 300 \mathrm{~mm}$, as seen from the inside of the Seaport main hall, making the supporting structure of the steel bar structure of the glazed skylight (Figures 4, 5, 6). 


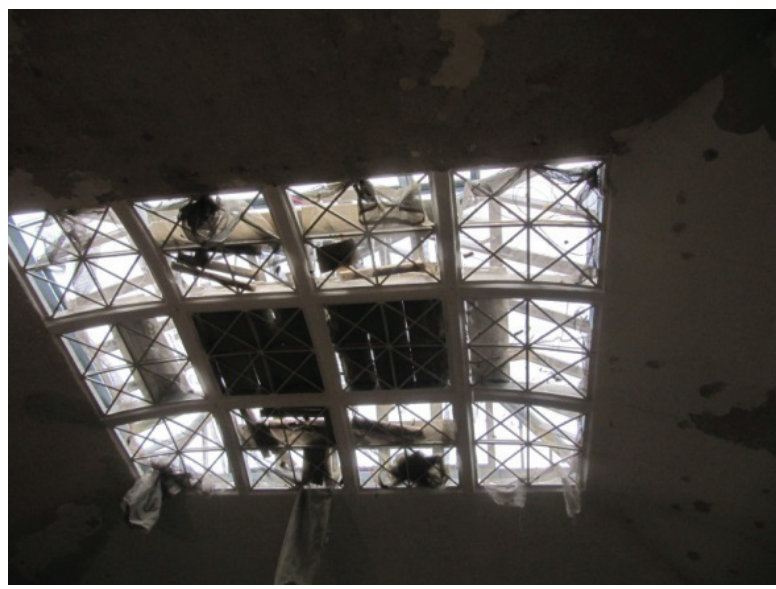

Fig. 4. Reinforced concrete grid of the skylight as seen from the inside of the Seaport Hall

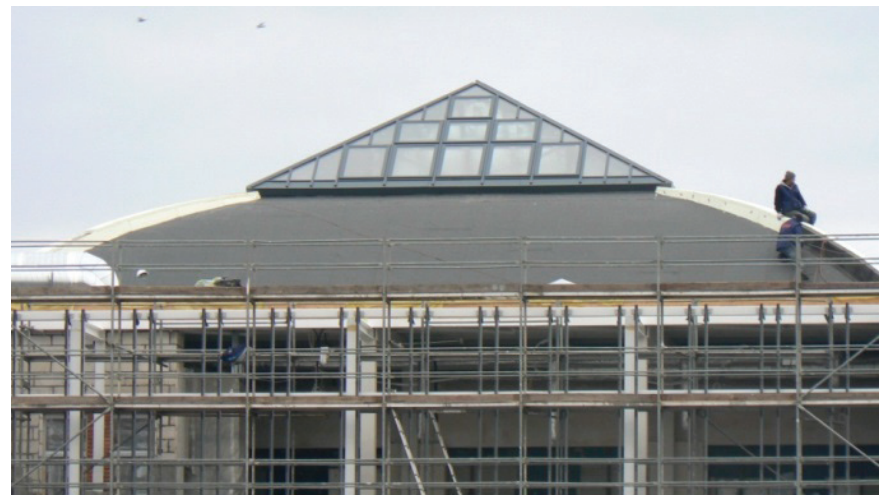

Fig. 5. The dome with the skylight from the side of the French Quay (December 2013)

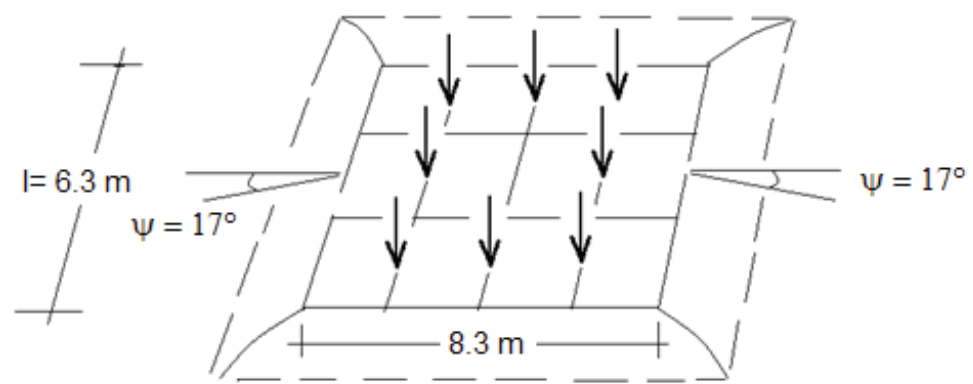

Fig. 6. Sketch of the reinforced concrete grid at the top of the dome under the load of the pyramidal skylight 
Data:

- Deadweight of the grid:

Ggrid $=0.2 \cdot 0.3 \cdot(4 \cdot 8.3+5 \cdot 6.3) \cdot 25=3.9 \mathrm{~m}^{3} \cdot 25=97.5 \mathrm{kN}$

- Glazing of the pyramid $11.89 \mathrm{kN}$

- $\quad$ Steel structure -

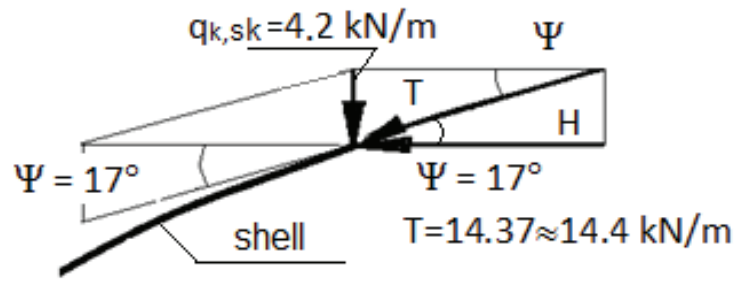

Fig. 7. Load on the circumferential beam at the contact point with the shell

Vertical load on the circumferential grid beam

$$
q_{k, s k}=\frac{122.43 k N}{2(8.3+6.3)}=4.193 \cong 4.2 \mathrm{kN} / \mathrm{m}
$$

$\operatorname{ctg} \psi=3.271 ; \cos \psi=0.956$

Horizontal force (Figure 7)

$\mathrm{H}=\mathrm{q}_{\mathrm{sk}} \cdot \operatorname{ctg} \psi=4.2 \cdot 3.27=13.74 \approx 14 \mathrm{kN} / \mathrm{mb}$

$$
T=\frac{H}{\cos \Psi}=\frac{13.74}{0.956}=14.37 \mathrm{kN} / \mathrm{mb}
$$

Ignoring the share of oblique ribs that partially take over $\mathrm{T}$ force (regarding the small cross-section and weak concrete) the compressive stress at the contact point with the circumferential beam of the skylight is equal to:

$$
\sigma_{\varphi 1}=\frac{-14.4}{0.06 \cdot 1.00}=-240 \mathrm{kN} / \mathrm{m}^{2}=-0.24 \mathrm{MPa}<<\mathrm{f}_{\mathrm{ctm}}=2.5 \mathrm{MPa}
$$




\section{The STATE OF EFForts OF THE DOME ACCORDING to \\ F. DisCHINGER'S METHOD}

\section{Shell}

The internal forces in the shell are calculated out from the equations of equilibrium $(4.1 \div 4.3)$ of an element of the single curvature shell, where $p_{x}, p_{y}, p_{z}$ are components of the load (Figure. 8).

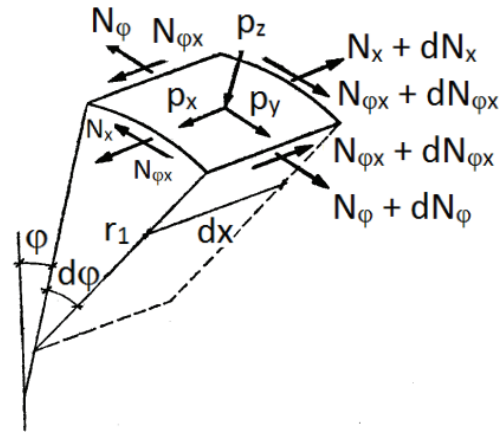

Fig. 8. Internal forces in the single curvature shell

$$
\begin{aligned}
& \frac{\partial N_{\varphi x}}{\partial x}+\frac{\partial N_{\varphi}}{r_{1} \partial \varphi}+p_{y}=0 \\
& \frac{\partial N_{x}}{\partial x}+\frac{\partial N_{\varphi x}}{r_{1} \partial \varphi}+p_{x}=0
\end{aligned}
$$

$$
N_{\varphi}+p_{z} \cdot r_{1}=0
$$

In the case of the Gdynia Seaport Dome, at the surface joints of the shell, four corners were strengthened with external ribs of a rectangular cross-section $b=300 \mathrm{~mm}$ and a variable height $\mathrm{h}$ from 450 to $300 \mathrm{~mm}$.

The state of stress of the dome in such a way may be considered as the superposition of two states, one of them determining the work of the cylindrical shell transmitting the load along the edge lines, and the other transmitting forces from the shell to the edge elements of the support of circumferential beams at the corners $\mathrm{N}_{1} \div \mathrm{N}_{4}$ (Figure $9 \mathrm{~b}$ ).

Passing over the procedure of making use of the F. Dischinger's formulas, the tangential forces $N_{\varphi x}$, meridian $N_{\varphi}$, and horizontal parallel $N_{x}$, were calculated assuming constant radius of curvatures for the shell $\mathrm{r}_{1 \text { const }}=15 \mathrm{~m}$, and for the oblique ribs $\mathrm{r}_{2}=$ const $=22 \mathrm{~m}$. The above values of the radius resulted from geodesic measurements 
(Figures 9 and 10). The weight of the shell together with insulation was assumed as $\mathrm{g}_{\mathrm{k}}=2.2 \mathrm{kN} / \mathrm{m}^{2}$

a)

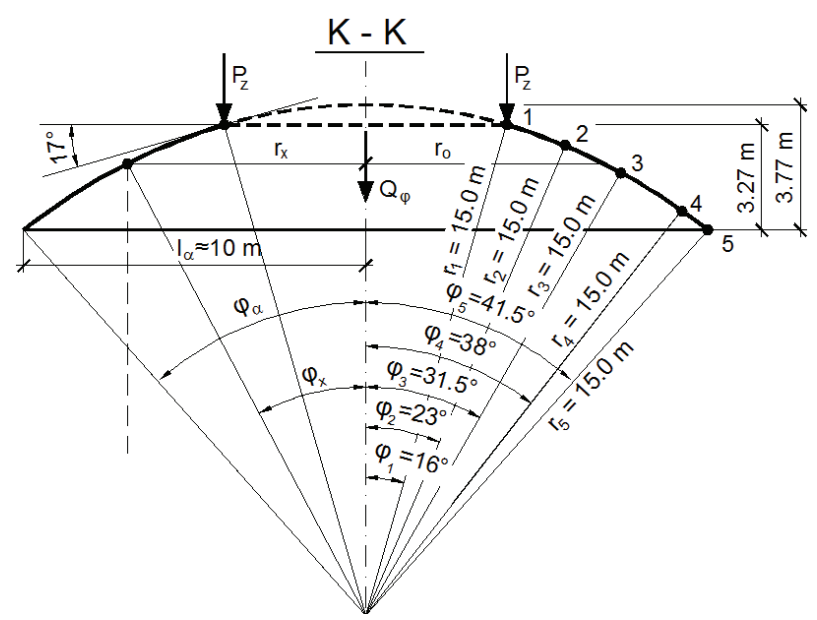

b)

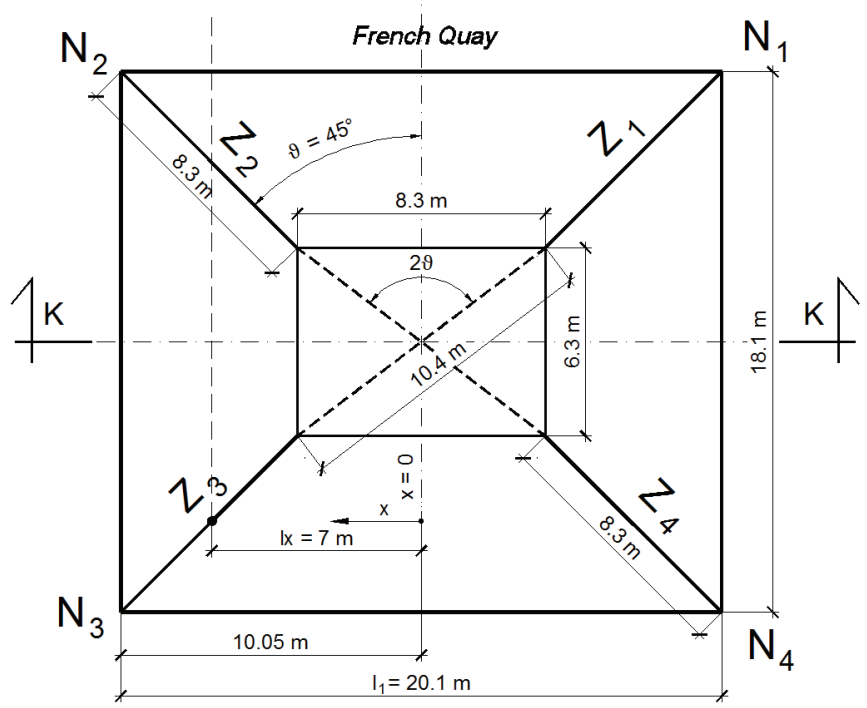

Fig. 9. Approximation of the shape of the shell to the Dischinger's formulas [5]:

a) in vertical cross-section, b) in horizontal projection 
Forces of the symmetrical loads (deadweight , $\mathrm{g}_{\mathrm{k}}$ ”) imposed on the shell, for the vertical cross-section in the center of the span of the shell on the northern side $(\mathrm{x}=0$, Figure. $9 \mathrm{~b}$ ) were calculated from the following formulas:

Meridional forces:

$$
N_{\varphi}=p_{z} \cdot r=-g \cdot r \cdot \cos \varphi
$$

Tangential forces:

$$
N_{\varphi x}=-2 \cdot g \cdot x \cdot \sin \varphi
$$

Horizontal paralell forces for the midline $\mathrm{x}=0$ from the formula

$$
\begin{gathered}
N_{x,(x=0)=} \frac{g \cdot r}{\cos ^{2} \vartheta \cdot \sin ^{2} \varphi}\left\{1-\cos \varphi\left[1+4 \sin ^{4} \varphi \cdot \sin ^{2} \vartheta+\sin ^{2} \varphi \cdot\right.\right. \\
\left.\left.\cos ^{2} \vartheta\right]\right\}-g \cdot r \cdot \operatorname{tg}^{2} \vartheta \cdot \sin \varphi \cdot \sin 2 \varphi
\end{gathered}
$$

where : $\vartheta=45^{\circ}$ (Figure. $9 \mathrm{~b}$ )

Longitudinal forces in the corner element originating from tangential stresses of the adjacent shells were calculated acording to the formula:

$$
S_{\varphi}=2 g \cdot r^{2} \cdot \operatorname{tg} \vartheta \cdot\left[\left(1+\sin ^{2} \varphi\right) \cdot \cos 2 \varphi-1\right] \cdot \sqrt{1+\frac{\operatorname{ctg}^{2} \varphi}{\cos ^{2} \vartheta}}
$$

Results of the calculation are compiled in Tables 1 and 2 .

Table 1.

Horizontal (parallel) for the midline $\mathrm{N}_{\mathrm{x}(\mathrm{x}=0)}$ and meridian forces $\mathrm{N}_{\varphi}$ in the shell of the dome

\begin{tabular}{|c|c|c|c|c|c|c|}
\hline Angle $\varphi_{\mathrm{i}}$ & $\mathrm{g}\left[\mathrm{kN} / \mathrm{m}^{2}\right]$ & $\begin{array}{c}\mathrm{r} \\
{[\mathrm{m}]}\end{array}$ & $\begin{array}{c}\vartheta \\
{\left[{ }^{\circ}\right]}\end{array}$ & $\begin{array}{c}\varphi \\
{\left[{ }^{\circ}\right]}\end{array}$ & $\begin{array}{c}\mathrm{N}_{\varphi} \\
\text { formula (4.4) } \\
{[\mathrm{kN} / \mathrm{m}]}\end{array}$ & $\begin{array}{c}\mathrm{N}_{\mathrm{x}(\mathrm{x}=0)} \\
\text { formula (4.6) } \\
{[\mathrm{kN} / \mathrm{m}]}\end{array}$ \\
\hline$\varphi_{1}$ & 2.2 & 15.0 & 45 & 16 & -31.72 & -12.53 \\
\hline$\varphi_{2}$ & 2.2 & 15.0 & 45 & 23 & -30.38 & -23.84 \\
\hline$\varphi_{3}$ & 2.2 & 15.0 & 45 & 31.5 & -28.14 & -38.60 \\
\hline$\varphi_{4}$ & 2.2 & 15.0 & 45 & 38 & -26.00 & -48.23 \\
\hline$\varphi_{5}$ & 2.2 & 15.0 & 45 & 41,5 & -24.72 & -52.09 \\
\hline
\end{tabular}


Table 2.

Longitudinal forces in corner elements of the shell $\mathrm{S}_{\varphi}$

\begin{tabular}{|c|c|c|c|c|c|}
\hline $\begin{array}{c}\text { Angle } \\
\varphi_{\mathrm{i}}\end{array}$ & $\mathrm{g}\left[\mathrm{kN} / \mathrm{m}^{2}\right]$ & $\begin{array}{c}\mathrm{r} \\
{[\mathrm{m}]}\end{array}$ & $\begin{array}{c}\vartheta \\
{\left[{ }^{\circ}\right]}\end{array}$ & $\begin{array}{c}\varphi \\
{\left[{ }^{\circ}\right]}\end{array}$ & $\begin{array}{c}\mathrm{S}_{\varphi} \\
\text { formula (4.7) } \\
{[\mathrm{kN}]}\end{array}$ \\
\hline$\varphi_{1}$ & 2.2 & 15.0 & 45 & 16 & 170.85 \\
\hline$\varphi_{2}$ & 2.2 & 15.0 & 45 & 23 & 210.20 \\
\hline$\varphi_{3}$ & 2.2 & 15.0 & 45 & 31.5 & 212.68 \\
\hline$\varphi_{4}$ & 2.2 & 15.0 & 45 & 38 & 177.50 \\
\hline$\varphi_{5}$ & 2.2 & 15.0 & 45 & 41,5 & 145.22 \\
\hline
\end{tabular}

\section{Oblique rib at the contact point of the shells}

The weight of $1 \mathrm{~m}^{2}$ of the reinforced concrete grid together with the glazed skylight was equal to:

$$
g_{k r}=\frac{122.43}{6.3 \cdot 8.3}=2.14 \mathrm{kN} / \mathrm{m}^{2} \cong \mathrm{g}_{\mathrm{k},(\text { of the shell) }}=2.2 \mathrm{kN} / \mathrm{m}^{2} .
$$

In the horizontal projection (for $\varphi=38^{\circ}$ ) the length of the rib is equal to $1_{\varphi}=r_{2} \cdot \sin 38^{\circ}=13.5 \mathrm{~m}$, (Figure. 10).

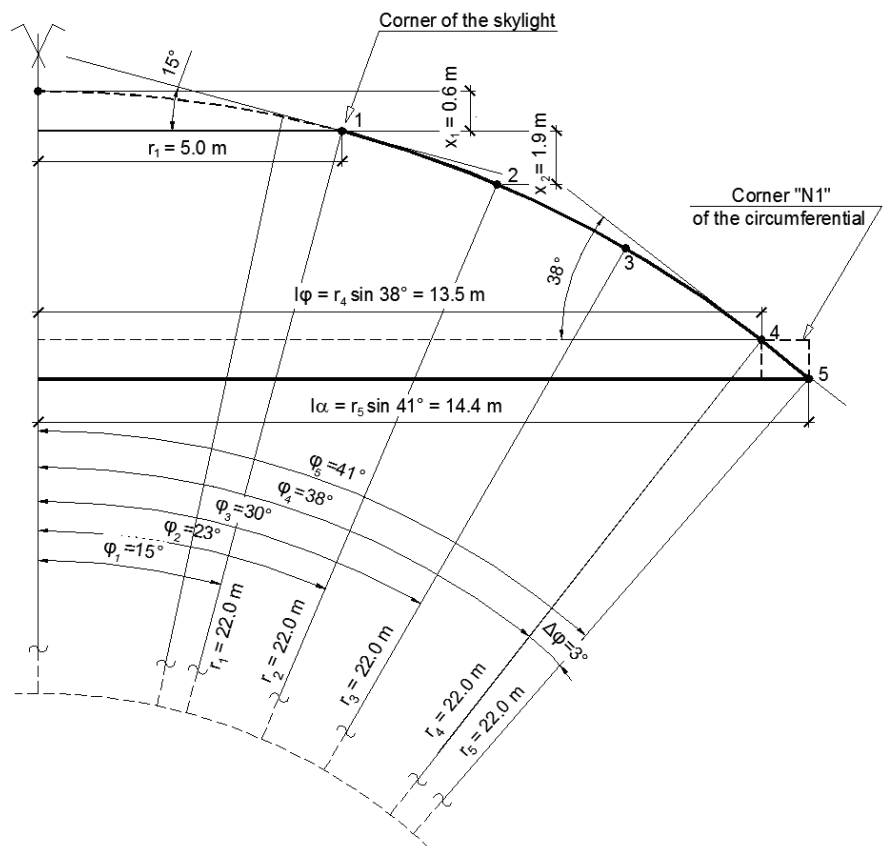

Fig. 10. Curvature of the oblique ribs on the joint of the shells $r_{\dot{z}}=22.0 \mathrm{~m}$ 
Forces $\mathrm{S}_{\varphi} \mathrm{i} \mathrm{N}_{\mathrm{x}}$ of the deadweight of rib $\mathrm{P}$ was calculated from the formula:

$$
S_{\varphi i}=-\frac{P \cdot r \cdot E\left(\frac{\pi}{2 n}, \varphi\right)}{\cos \frac{\pi}{2 n} \cdot \sqrt{\frac{\cos ^{2}\left(\frac{\pi}{2 n}\right) \cdot \operatorname{tg}^{2} \varphi_{i}}{1+\cos ^{2}\left(\frac{\pi}{2 n}\right) \cdot \operatorname{tg}^{2} \varphi_{i}}}}
$$

where:

$E\left(\frac{\pi}{2 n}, \varphi\right)$ is the value of the eliptic integral of the second order [4]

$$
E(\alpha, \varphi)=\int_{0}^{\varphi} \sqrt{1-\sin ^{2} \alpha \cdot \sin ^{2} \varphi \cdot d \varphi}=E\left(\frac{\pi}{2 n}, \varphi\right)
$$

The horizontal parallel force in the corner of the shell was calculated from the formula:

$$
N_{x}=-\frac{P}{2 \cos ^{2} \frac{\pi}{2 n} \cdot \sin \frac{\pi}{2 n}}\left[\operatorname{ctg} \varphi \sqrt{1-\sin ^{2} \frac{\pi}{2 n} \cdot \sin ^{2} \varphi}-\frac{E\left(\frac{\pi}{2 n}, \varphi\right)}{\sin ^{2} \varphi}\right]
$$

The load of the deadweight of the rib $\mathrm{P}=\mathrm{p}_{\dot{\mathrm{Z}}}=3.0[\mathrm{kN} / \mathrm{m}]$, number of intersected cylindrical shells $n=2$, number of ribs $2 n=4$.

Table 3.

Forces in the shell from the rib weight in corner elements

\begin{tabular}{|c|c|c|c|c|c|c|c|c|}
\hline $\begin{array}{c}\text { Angle } \\
\varphi_{\mathrm{i}}\end{array}$ & $\begin{array}{c}\mathrm{P}=\mathrm{p}_{2}[\mathrm{kN} / \\
\left.\mathrm{m}^{2}\right]\end{array}$ & $\begin{array}{c}\mathrm{r} \\
{[\mathrm{m}]}\end{array}$ & $\mathrm{n}$ & $E\left(\frac{\pi}{2 n}, \varphi\right)$ & $\begin{array}{c}\vartheta \\
{\left[{ }^{\circ}\right]}\end{array}$ & $\begin{array}{c}\varphi \\
{\left[{ }^{\circ}\right]}\end{array}$ & $\begin{array}{c}\mathrm{S}_{\varphi} \\
\text { formula }(4.8) \\
{[\mathrm{kN}]}\end{array}$ & $\begin{array}{c}\mathrm{N}_{\mathrm{x}} \\
\text { formula }(4.10) \\
{[\mathrm{kN} / \mathrm{m}]}\end{array}$ \\
\hline$\varphi_{1}$ & 3 & 22.0 & 2 & 0.2603 & 45 & 15 & -130.51 & 0.92 \\
\hline$\varphi_{2}$ & 3 & 22.0 & 2 & 0.396 & 45 & 23 & -128.57 & 1.4 \\
\hline$\varphi_{3}$ & 3 & 22.0 & 2 & 0.512 & 45 & 30 & -126.44 & 1.82 \\
\hline$\varphi_{4}$ & 3 & 22.0 & 2 & 0.64 & 45 & 38 & -123.53 & 2.27 \\
\hline
\end{tabular}


Table 4.

Forces for the load $(\mathrm{g}+\mathrm{P})$

\begin{tabular}{|c|c|c|c|c|}
\hline $\begin{array}{c}\text { Kąt } \\
\varphi_{\mathrm{i}}\end{array}$ & $\begin{array}{c}\mathrm{N}_{\mathrm{x}, \mathrm{x}=0} \\
{[\mathrm{kN} / \mathrm{m}]}\end{array}$ & $\begin{array}{c}\mathrm{S}_{\varphi} \\
{[\mathrm{kN}]}\end{array}$ & $\begin{array}{c}\mathrm{N}_{\varphi} \\
{[\mathrm{kN} / \mathrm{m}]}\end{array}$ & $\begin{array}{c}\mathrm{N}_{\varphi x} \\
{[\mathrm{kN} / \mathrm{m}]}\end{array}$ \\
\hline$\varphi_{1}$ & -11.6 & 40.3 & -31.7 & -5.0 \\
\hline$\varphi_{2}$ & $-22,4$ & 81.6 & -30.4 & -10.1 \\
\hline$\varphi_{3}$ & -36.8 & 86.2 & -28.14 & -18.0 \\
\hline$\varphi_{4}$ & -46.0 & 54.0 & -26.00 & -25.0 \\
\hline
\end{tabular}

Values of forces shown in Tables 1-4 were then compared with the values numerically obtained (MES) regarding the spacial model of the dome and with the assumption of elastic properties of the material. It was assumed that the compatibility of the obtained values was sufficient.

\section{NUMERICAL ANALYSIS}

In the next part of the paper, the results of the internal forces of the Dome calculated using numerical methods MES, are presented. For this purpose, a model of computation was formulated allowing broader consideration of both the remaining actions, thermal one, and the influence of variable boundary conditions. Besides, out of the comparison of the results obtained with the use of both methods, the possibility of comprehensive presentation of the results of calculations in the form of various diagrams and maps was obtained.

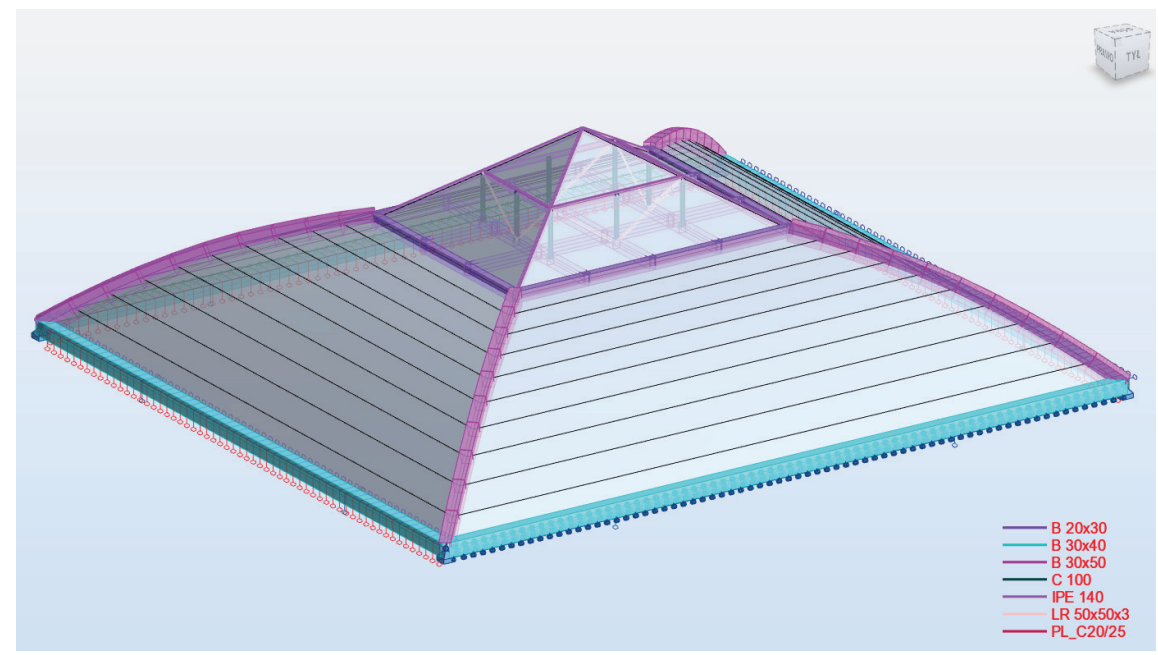

Fig. 11. Digitization of the computational model. The legends present the adopted transversal cross-sections 
The calculation model of the Dome is a spacial structure composed of a shell and rods of a curvature mapping the ribs of the Dome, and of the reinforced concrete grid supporting the steel structure of the pyramidal skylight.

For the MES calculations, the computational software Autodesk Robot Structural Analysis was applied, using the linear elastic analysis.

For the statical calculations, the material parameters were assumed, determined from the experimental research of the present state of the concrete of beam elements corresponding to the $\mathrm{C} 12 / 15$ class, while for the shell to the $\mathrm{C} 20 / 25$ class. The members of the steel structure were adopted for steel of S235 class.

On the perimeter of the Dome, along the line of circumferential beams, the hinged non-slidable supports were assumed, while the shift from the side of the French Quay in the horizontal plane was released. The above boundary condition resulted from structural solution adopted in the postwar reconstruction. At the contact point of the ribs of the Dome with circumferential beams (N1 to N4) the unsusceptible hinged non-slidable nodes were adopted. View of the adopted supports is shown in Figure 11.

The considered interactions in the computational model include, apart from the deadweight of the structure and the remaining constant complementary loads, the climatic actions, i.e. snow, wind, and thermal loads. The determined value of the temperature gradient for non-insulated ribs during winter season was equal to $\Delta T_{M}=-20^{\circ} \mathrm{C}$.

The assigned stresses in the shell, both in meridian and parallel direction caused by the combination of constant and climatic loads (temperature gradient included) are minor in relation to the high strength of concrete of the Dome (Figure 12, Figure 13).

Considerably higher stresses, tension stresses including, occurred in the non-insulated oblique ribs of the shell where the strength of concrete in relation to the strength of the shell decreased nearly twice which caused intensive cracking. In Figure 14 and 15 the diagrams of normal forces and bending moments in the ribs of the shell are presented regarding all possible influences, including the unfavourable temperature gradient.

According to the climatic changes, both in winter and summer, diversified inner and outer temperatures emerged on the contact points of the shell with non-insulated rib. In the extremally unfavourable situation the emerging gradients $\Delta T_{m}=-20^{\circ} \mathrm{C}$ caused major tension stresses in the sticking out beam resulting in cracks concentrated in the upper part of the transverse cross-section of beams (Figure. 16).

The situation radically changed after insulation of the ribs sticking out above the upper edge of the shell. Assuming the thickness of the insulation as $50 \mathrm{~mm}$ of poliurethane plate, the value of bending moments and thus of the tension stresses, decreased by over three times, what is presented in Figure 17. 


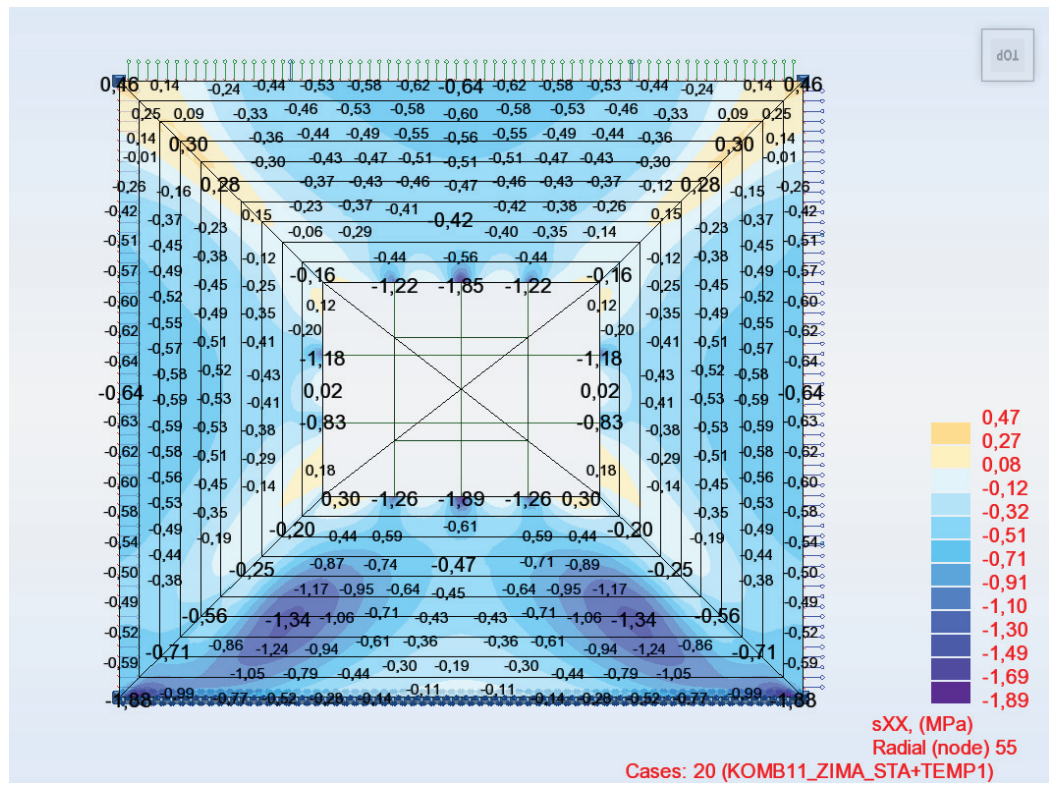

Fig. 12. Map of the stresses in the inner mid layer of the shell in the meridian direction. (Combination of winter-time loads)

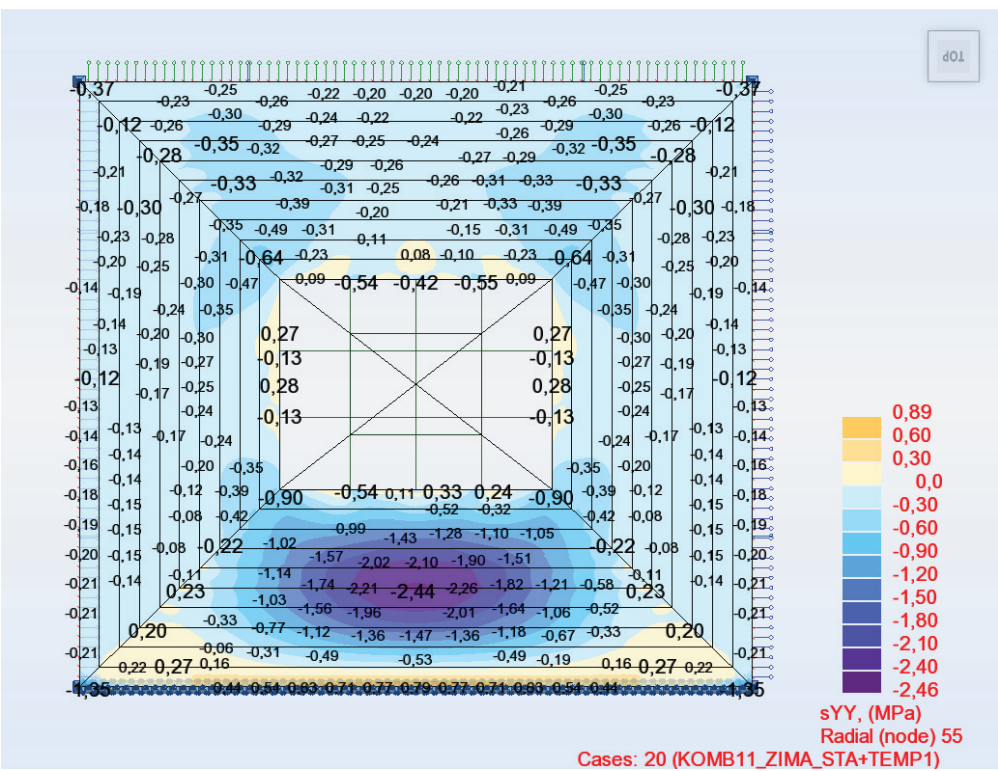

Fig. 13. Map of the stresses within the inner layer of the shell in the parallel direction. (Combination of winter-time loads) 


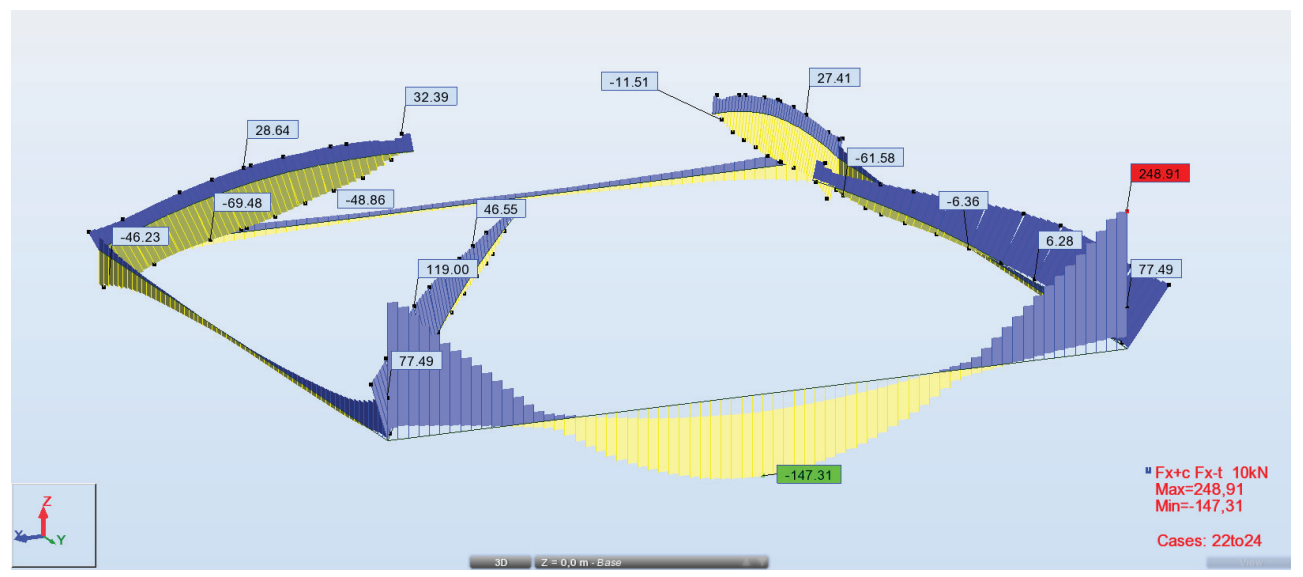

Fig. 14. Envelope of normal forces of non-insulated ribs of the Dome (combination of all loads)

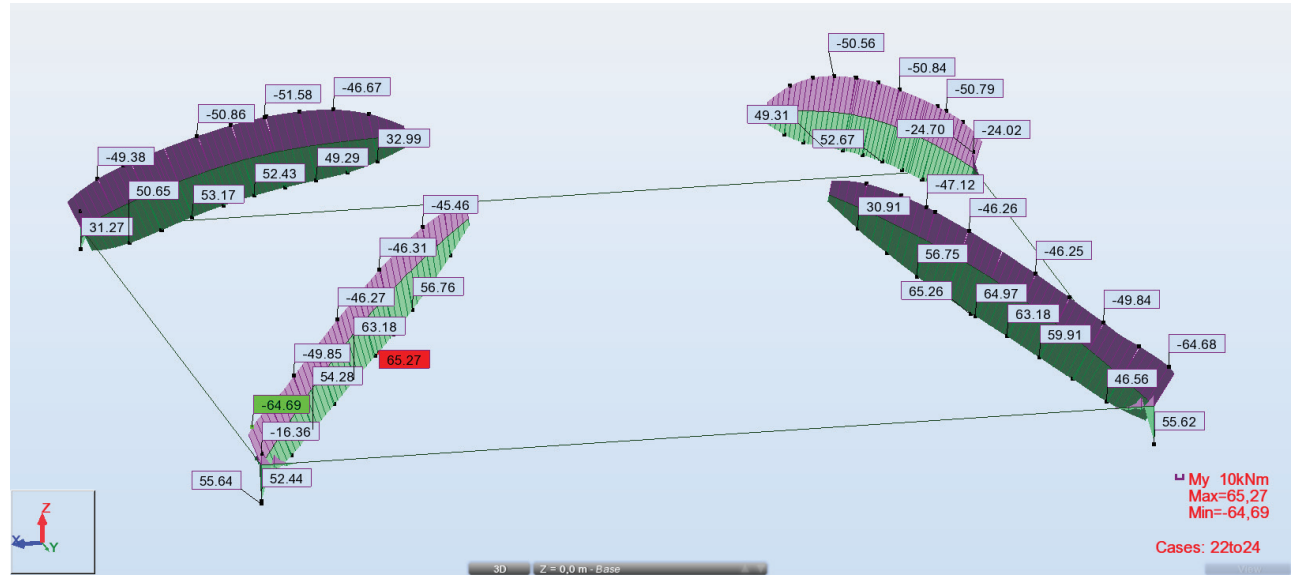

Fig. 15. Envelope of bending moments of non-insulated ribs of the Dome (combination of all loads) 


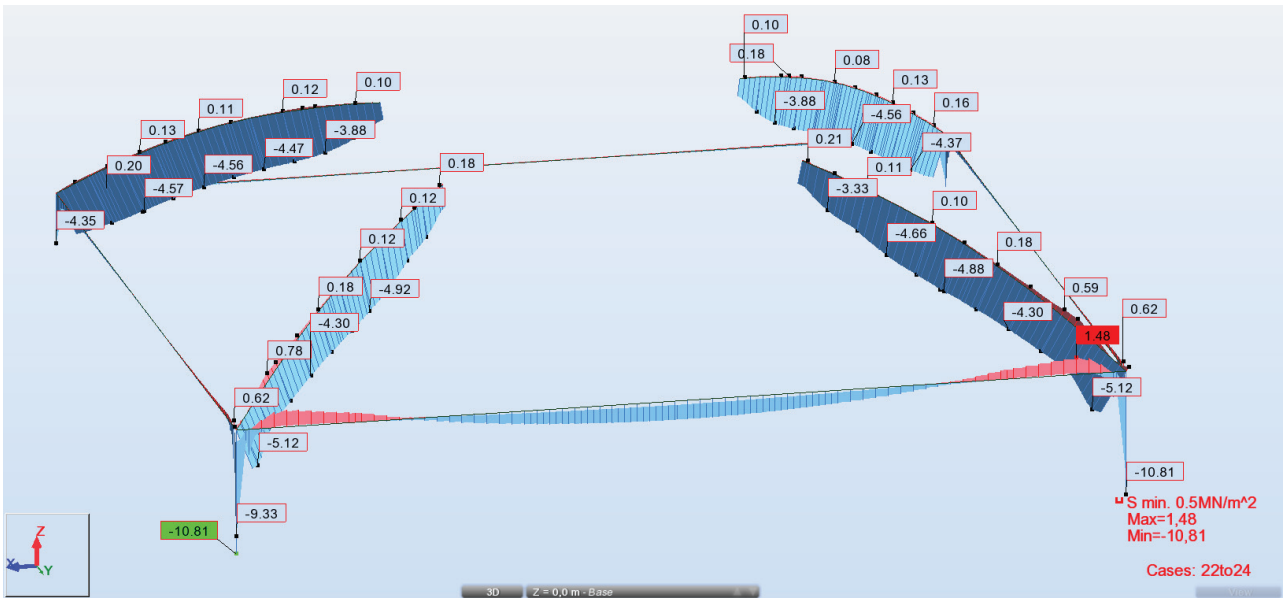

Fig. 16. Envelope of minimum stresses ([-] tension) in the non-insulated ribs of the Dome (combination of all loads)

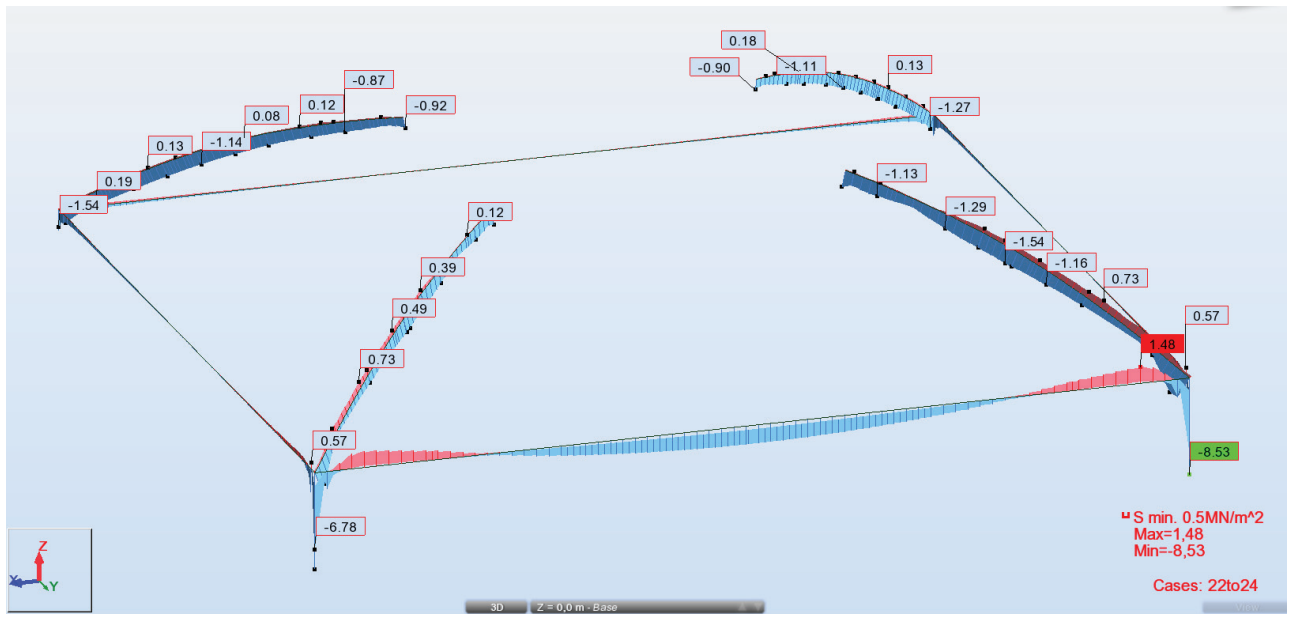

Fig. 17. Envelope of minimum stresses ([-] tension) after insulating of oblique ribs of the Dome (combination of all loads)

The so far exploitation of the Dome of the Gdynia Seaport, as well as carried out tests, and statical and strength calculations, confirm that the strength of the shell concrete after 80 years of exploitation is so high that, under the minor compressing stresses in both directions, the safety coefficient is sufficiently high. 
Unlike the shell, the concrete resistance of the ribs of the Dome is significantly lower. As it results from the resistance analysis, due to the lack of insulation, the ribs were working in unfavourable conditions, especially in the winter season. Therefore, the supposition that the decrease of the concrete resistance and cracking of the ribs occurred as a result of unfavourable thermal conditions in winter seasons is justified. As it results from the executed analysis, the situation will be radically improved after insulating of the ribs and reparing the occurred damage. The repair works of the Dome, including the recommended by the authors insulation of the ribs, were carried on in December, 2013. In Figure. 18, the exemplary insulation of the north-eastern ribs of the Dome is presented.

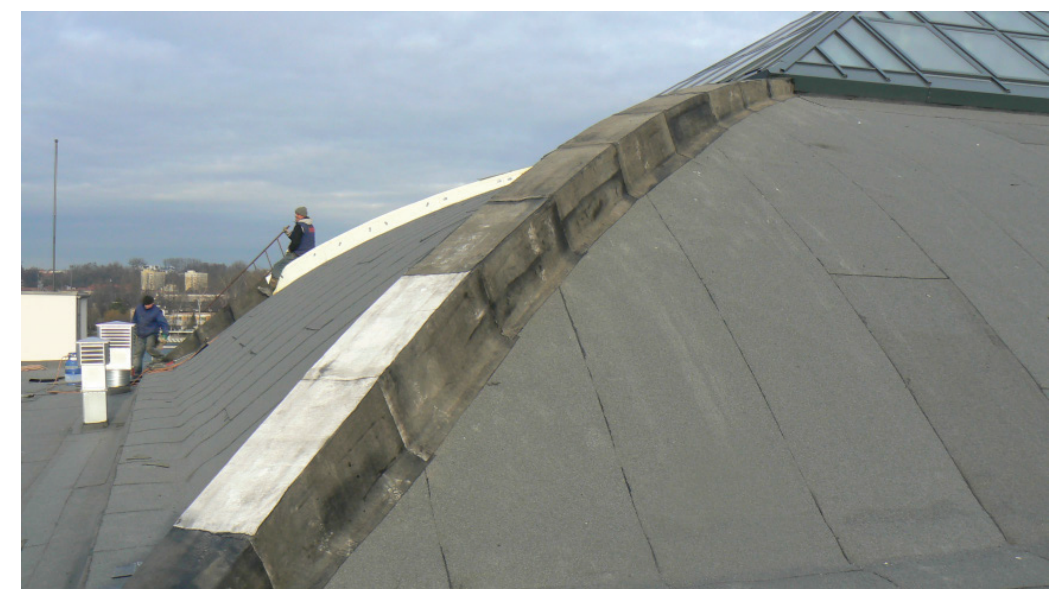

Fig. 18. View of the insulated ribs of the dome of Gdynia Seaport Dome (December 2013)

\section{Conclusions}

The $60 \mathrm{~mm}$ thin-walled shell of the Gdynia Seaport has been through its 80 years long exploitation exposed to unfavourable marine climate. The revealed visible varied damages in form of cracks, local loss of concrete, and reinforcement corrosion raised justified concern as to possibility of further exploitation. Particularily large local damages of concrete structure occurred in near-joint areas of the shell, that is why a specialized company was commissioned to perform the repair. The carried out static-strength analysis, on the basis of which the ribs insulation and local repairs of the shell concrete was performed, made it possible to take decision on permitting the dome for further few dozen years of exploitation. 


\section{REFERENCES}

1. Dischinger F., Die Theorie der Vieleckkupelln und die Zusammenhänge mit der einbeschriebenen Rotationsschalen, Beton und Eisen 1929

2. Dischinger F., Schalen und Rippenkuppeln, Handbuch für Eisenbetonbau, t. VI, Berlin 1930

3. Dischinger F., Rüsch H., Die Grossmarkthalle in Leipzig, Beton und Eisen 29/1929

4. Stachurski W., Concrete structures, vol. 4. Warszawa, Arkady 1991 [in Polish]

5. Godycki-Ćwirko T., Technological expertise of the Seaport Gdynia Dome in the aspect of safety and durability, Gdańsk, Nov. 2013, [in Polish]

6. Majewski T., Technological expertise, Sept. 2013

7. FiАєко S., The high-performance aggregation element-by-element iterative solver for the large-scale complex shell structure problems, Archives of Civil Engineering, 45, 2, 193-207, 1999 
